\title{
Parecoxib Provides Analgesic and Opioid-Sparing Effects Following Major Orthopedic Surgery: A Subset Analysis of a Randomized, Placebo-Controlled Clinical Trial
}

Efrain Diaz-Borjon · Armando Torres-Gomez · Margaret Noyes Essex ·

Patricia Salomon $\cdot$ Chunming Li $\cdot$ Raymond Cheung $\cdot$ Bruce Parsons

Received: December 19, 2016 / Published online: March 2, 2017

(C) The Author(s) 2017. This article is published with open access at Springerlink.com

\section{ABSTRACT}

Introduction: Orthopedic surgeries are among the most common and most painful surgeries performed. A multimodal analgesic approach is recommended to reduce opioid consumption, provide effective pain relief, and improve outcomes following surgery. This study examined the efficacy and opioid-sparing effects of parecoxib following major orthopedic surgery.

Enhanced content To view enhanced content for this article go to http://www.medengine.com/Redeem/ 6E87F06078C73AD1.

E. Diaz-Borjon

Orthopedics and Traumatology, Hospital Angeles Lomas, Huixquilucan, Mexico

A. Torres-Gomez

Orthopaedics, ABC Medical Center, Mexico City, Mexico

M. N. Essex $(\bowtie) \cdot R$. Cheung · B. Parsons

Global Medical Affairs, Pfizer Inc, New York, NY, USA

e-mail: Margaret.essex@pfizer.com

P. Salomon

Pain Division for Latin America, Pfizer Inc, Mexico City, Mexico

C. $\mathrm{Li}$

Statistics, Pfizer Inc, Madison, NJ, USA
Methods: This subset analysis of a large, multicenter, randomized, double-blind, placebo-controlled study of parecoxib examined treatment effects on postoperative pain severity, pain interference with function, opioid consumption, occurrence of opioid-related symptoms, safety, and patient satisfaction following major orthopedic surgery.

Results: Pain scores were significantly lower in the parecoxib group $(n=142)$ compared with placebo $(n=139)$ on day $2(-22 \% ; p<0.001)$ and day $3(-17 \% ; p=0.004)$. Pain interference with function scores were also significantly lower in the parecoxib group on day $2(-32 \%$; $p<0.001)$ and day $3(-27 \% ; p=0.003)$ relative to placebo. Additionally, significantly less supplemental morphine was required in the parecoxib group relative to placebo through $24 \mathrm{~h}$ $(-28 \% ; p=0.008)$ and $48 \mathrm{~h}(-33 \% ; p<0.001)$. Patients in the parecoxib group had a reduced risk of experiencing opioid-related symptoms including fatigue, drowsiness, inability to concentrate, confusion, nausea, constipation, and confusion on day 2 and/or day 3. Finally, more patients receiving parecoxib (42\%) rated treatment as "excellent" compared to those receiving placebo (21\%).

Conclusions: These findings support the use of parecoxib for the management of pain following major orthopedic surgery.

Keywords: Opioid-sparing; Orthopedic surgery; Parecoxib; Postoperative pain 


\section{INTRODUCTION}

Orthopedic surgeries are among the most common major surgeries and their incidence has grown over the past 15 years [1-3]. In 2011 there were approximately 645,062 total knee replacements, 465,070 spinal fusions, and 306,600 total hip replacements in the USA alone [2]. These types of surgeries, particularly knee and hip replacements, are expected to dramatically increase over the next 15 years [3]. Orthopedic surgeries, however, are also among the most painful surgeries, and moderate-to-severe postoperative pain is not uncommon [4-6]. Pain management is of utmost importance in the early stages after total knee and hip arthroplasty, because prompt and extensive physical rehabilitation and activity are encouraged, but may be restrained by pain. Indeed, though surgeries such as total joint replacement have a high success rate, they are underutilized, in part, because of fear of pain $[7,8]$. Furthermore, there is a high rate of patient dissatisfaction following total knee arthroplasty, and pain is the most significant predictor of dissatisfaction [9]. Thus, the selection and use of effective analgesics are important considerations following major orthopedic procedures to ensure that the patient can rest at night and tolerate therapy during the day.

Appropriate pain control after orthopedic surgeries can enhance early functional recovery $[10,11]$. Managing acute pain begins in the preoperative period and continues throughout the postoperative phase. Multimodal analgesia can provide superior control of postsurgical pain compared with a traditional opioid analgesic regimen [10, 12]. Although opioids are effective against moderate-to-severe pain, they are frequently associated with a variety of unwanted side effects including drowsiness, confusion, nausea, itching, and constipation [13-15]. These side effects add stress to the patient and may require them to undergo supplementary treatments for the management of these effects, further delaying mobilization and increasing recovery/hospitalization times $[16,17]$. In addition, though they are effective for pain at rest, opioids are less effective for movement-related pain which may be problematic during physical rehabilitation and early mobilization strategies $[18,19]$. As a result, to reduce overall opioid consumption and the occurrence of opioid-associated side effects, current treatment guidelines recommend a multimodal treatment strategy that incorporates non-steroidal anti-inflammatory drugs (NSAIDs), cyclooxygenase-2 inhibitors (COXIBs), and/or acetaminophen to supplement opioid use [20]. Multimodal analgesia has proven to be provide adequate pain control, assist in early recovery, and even allow for same-day discharge after total knee and hip replacement surgery [11].

Parecoxib, an injectable COXIB with long-acting duration, has been approved in over 80 countries as analgesia to reduce postoperative pain. Since parecoxib is selective for cyclooxygenase- 2 inhibition, it poses less risk for bleeding and gastrointestinal-related adverse events as compared to nonselective NSAIDs [21-24]. It also does not pose a risk for many of the central nervous system-related side effects that are associated with opioids. However, there are few studies in the literature that examine the analgesic efficacy and opioid-sparing effects of postoperative parecoxib administration in patients undergoing major orthopedic surgery. The current analysis, therefore, examines the efficacy and opioid-sparing effects of parecoxib following major orthopedic surgery [25].

\section{METHODS}

\section{Data Source}

Data were derived from a multicenter, randomized, double-blind, placebo-controlled clinical trial that examined the safety and efficacy of parecoxib followed by valdecoxib for postoperative pain resulting from a variety of non-cardiac surgeries [25]. The study was conducted at 113 site in 14 countries including the USA, Canada, Chile, Argentina, Australia, New Zealand, Bulgaria, Czech Republic, Poland, Romania, Ukraine, Finland, Israel, and South Africa. Here, we examine a large subset of patients from this clinical trial that includes all patients who underwent major orthopedic 
surgery. The study was approved by an institutional review board or independent ethics committee at each investigational center, and patients provided written informed consent before participation. The study was conducted in compliance with the Declaration of Helsinki of 1964, as revised in 2013, and all International Conference on Harmonization Good Clinical Practice Guidelines. Detailed methods of the trial can be found in the original publication but a brief summary is given below [25].

Following surgery, patients were admitted to the recovery room. Here, upon recovery from anesthesia, patients who met all pre-, intra-, and postoperative inclusion criteria were randomized in a double-blind manner to receive parecoxib/valdecoxib or matching placebo. On day 1 (the day of surgery and recovery from anesthesia) all patients randomized to the parecoxib/valdecoxib group received an initial 40-mg IV dose of parecoxib. These patients then received parecoxib $20 \mathrm{mg}$ (IV or IM) every $12 \mathrm{~h}$ through at least day 3 . Once the patient could tolerate oral medication, but no earlier than day 4 , they received 20-mg doses of oral valdecoxib through day 10, and patients assigned to receive placebo did so on a matching schedule. It should be noted that all assessments in this analysis were done when patients were receiving parecoxib (prior to switching to valdecoxib) (Table 1). As such the parecoxib/valdecoxib group will simply be referred to as the parecoxib group from here on. Patients with inadequate pain relief were allowed supplemental analgesia that consisted of IV administration of morphine sulfate through patient-controlled analgesia (PCA) or in IV/IM bolus as needed. No other supplemental analgesia was permitted.

\section{Efficacy Assessments Included in Current Analysis}

Patient demographics and baseline characteristics were summarized descriptively in all randomized patients.

Summed pain intensity over $24 \mathrm{~h}$ (SPI-24) was calculated on day 2 (the day after surgery) and day 3 for each treatment group as described previously and was derived from daily patient-reported pain assessments that ranged in score from $0=$ none to $3=$ severe pain [25]. An analysis of variance (ANOVA) model with treatment and country as factors and a last observation carried forward (LOCF) approach to missing data were used to compare SPI scores between the placebo and parecoxib treatment groups.

Composite pain interference with function scores were derived from five items of the pain interference with function question of the modified Brief Pain Inventory-short form (mBPI-sf) [26]. The five items included pain interference with general activity, mood, walking ability, relations with others, and sleep. Scores on day 2 (the day after surgery) and day 3 were compared between parecoxib and placebo treatment groups using a general linear model, with treatment and country as factors. A LOCF approach was used to account for missing data.

Table 1 Administration of parecoxib

\begin{tabular}{|c|c|}
\hline Treatment & Schedule \\
\hline $40 \mathrm{mg}$ IV parecoxib & One dose on day 1 (the day of surgery following recovery from anesthesia) \\
\hline $20 \mathrm{mg}$ IV or IM parecoxib & At 8:00 P.M. or midnight on day 1 and then every $12 \mathrm{~h}$ through at least day $3^{\mathrm{a}}$ \\
\hline \multicolumn{2}{|c|}{$\begin{array}{l}\text { Patients assigned to placebo received a matching placebo administered in the same manner as parecoxib } \\
\text { a Patients who received their first dose of } 40 \mathrm{mg} \text { IV parecoxib on day } 1 \text { between } 8: 00 \mathrm{~A} . \mathrm{M} \text {. and } 12: 00 \mathrm{P} . \mathrm{M} \text {. received their } \\
\text { first dose of } 20 \mathrm{mg} \mathrm{IV} / \mathrm{IM} \text { parecoxib at 8:00 P.M. on day } 1 \text {. Patients who received their first dose of } 40 \mathrm{mg} \text { IV parecoxib on } \\
\text { day } 1 \text { between 12:01 P.M. and 6:00 P.M. received their first dose of } 20 \mathrm{mg} \text { IV/IM parecoxib at midnight on day } 1 \text {. Patients } \\
\text { who received their first dose of } 40 \mathrm{mg} \mathrm{IV} \text { parecoxib after } 6: 01 \mathrm{P} . \mathrm{M} \text {. on day } 1 \text { did not receive a } 20 \mathrm{mg} \text { IV/IM dose of } \\
\text { parecoxib on day } 1 \text {. All patients received a } 20 \mathrm{mg} \text { IV/IM dose of parecoxib at 8:00 A.M. on Day } 2 \text { and then every } 12 \mathrm{~h} \\
\text { according to the schedule in Table } 1\end{array}$} \\
\hline
\end{tabular}


On day 2 ( $24 \mathrm{~h}$ post initial dose of study treatment) and day 3 ( $48 \mathrm{~h}$ post initial dose of study treatment), the cumulative amount of supplemental morphine consumed was determined and compared between the parecoxib and placebo groups. This comparison employed an ANOVA model with treatment and country as factors.

The occurrence of opioid-related symptoms (drowsiness, retching/vomiting, confusion, dizziness, itching, difficulty with urination, constipation, inability to concentrate, nausea, and fatigue) was determined on day 2 (the day after surgery) and day 3 using the Opioid-Related Symptom Distress Scale (ORSDS) [14]. The relative risk (RR; parecoxib versus placebo) was calculated for each particular symptom on the basis of the percentage of patients experiencing that symptom in each treatment group. Statistical significance was assessed using a Fisher's exact test. An RR (parecoxib versus placebo) of experiencing $\geq 1, \geq 2$, and $\geq 3$ opioid-related symptoms was also determined for day 2 .

Physicians and patients evaluated the study medication at the time of transition from IV/IM to oral dosing using a scale from $1=$ poor to $4=$ excellent. These scores were compared between parecoxib and placebo treatment groups using a Cochran-Mantel-Haenszel test, controlling for country.

Safety was assessed by examining the occurrence of treatment-related adverse events (AEs). AEs were monitored for 7 days after receiving last dose, so both acute and non-acute events were recorded. The frequency of the most common AEs (those occurring in $\geq 2 \%$ of patients in either treatment group) was calculated for the placebo and parecoxib groups and summarized descriptively. NSAIDs and COXIBs have been associated with specific adverse events such as gastrointestinal events, cardiovascular events, and bleeding. Therefore, we also examined the frequency of these specific events by searching all treatment-emergent AEs using the Standardized Medical Dictionary for Regulatory Activities (version 19.0) Queries of embolic and thrombotic events; gastrointestinal perforation, ulceration, hemorrhage or obstruction; hemorrhage terms (excluding laboratory terms).
All statistical analyses were performed using the modified intent-to-treat population, which consisted of all randomized patients who received at least one dose of study medication. Analyses were performed using Statistical Analysis System software (SAS Institute, Cary, NC, USA). It should be noted that all assessments in this analysis were done at a time when patients in the parecoxib group were receiving IV or IM parecoxib and had not yet switched to oral valdecoxib.

\section{RESULTS}

The number of patients in the orthopedic subset who were randomized to treatment was 139 for the placebo group and 142 for the parecoxib group (Fig. 1). Basic patient demographics were similar between the placebo and parecoxib treatment groups (Table 2). The patient population was predominantly white and had a median age of approximately 61 years. The most common surgeries in both treatment groups were procedures involving the knee $($ placebo $=52.5 \% ; \quad$ parecoxib $=46.5 \%), \quad$ followed by procedures involving the hip (placebo $=21.6 \% ;$ parecoxib $=31.0 \%$ ) or the neck/spine $\quad($ placebo $=15.8 \%$; parecoxib $=12.7 \%$ ). Over $85 \%$ of all knee procedures were total knee replacements and over $95 \%$ of the hip procedures were total hip replacements. The number of patients receiving at least one dose of study medication was 138 in

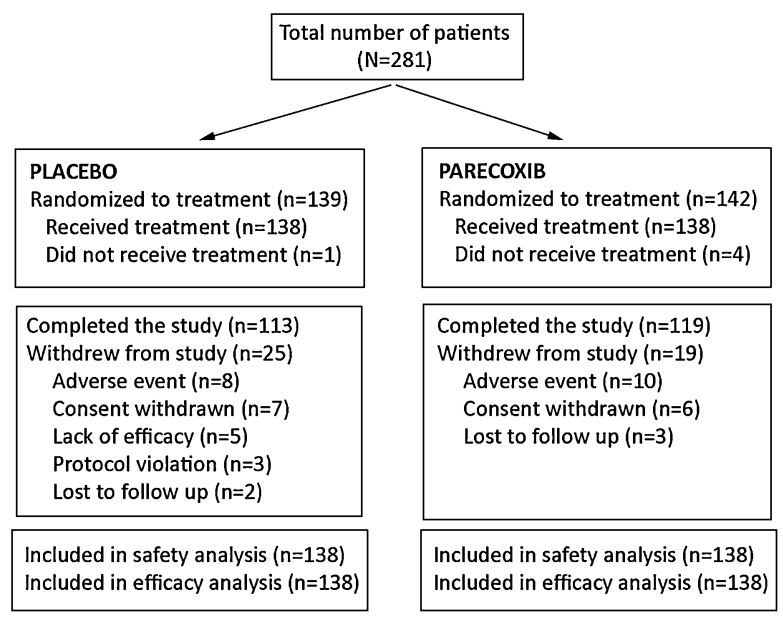

Fig. 1 Flow of patients through the trials 
Table 2 Demographics of patients included in the analysis

\begin{tabular}{|c|c|c|c|}
\hline & $\begin{array}{l}\text { Parecoxib } \\
(n=142)\end{array}$ & $\begin{array}{l}\text { Placebo } \\
(n=139)\end{array}$ & $p$ value \\
\hline Age, year & & & 0.461 \\
\hline Mean (SD) & $58.4(13.9)$ & $59.0(14.4)$ & \\
\hline Median & 60.5 & 60.8 & \\
\hline Range & $22-81$ & $19-81$ & \\
\hline Gender, $n(\%)$ & & & 0.475 \\
\hline Male & $65(45.8)$ & $70(50.4)$ & \\
\hline Female & $77(54.2)$ & $69(49.6)$ & \\
\hline Race, $n(\%)$ & & & 0.924 \\
\hline White & $131(92.3)$ & $130(93.5)$ & \\
\hline Black & $9(6.3)$ & $7(5.0)$ & \\
\hline Not listed & $2(1.4)$ & $2(1.4)$ & \\
\hline BMI, $\mathrm{kg} / \mathrm{m}^{2}$ & & & 0.591 \\
\hline Mean (SD) & $29.8(5.0)$ & $30.2(4.7)$ & \\
\hline Median & 29.7 & 29.7 & \\
\hline Surgery type, $n(\%)$ & & & 0.262 \\
\hline Knee & $66(46.5)$ & $73(52.5)$ & \\
\hline Hip & $44(31.0)$ & $30(21.6)$ & \\
\hline Neck/spine & $18(12.7)$ & $22(15.8)$ & \\
\hline Ankle/foot/bunion & $9(6.3)$ & $6(4.3)$ & \\
\hline Arm/shoulder/hand & $4(2.8)$ & $8(5.8)$ & \\
\hline Other & $1(0.7)$ & $0(0.0)$ & \\
\hline
\end{tabular}

Percentages in the table may not add up to 100 because of rounding

$S D$ standard deviation, $B M I$ body mass index

the placebo group and 138 in the parecoxib group.

Parecoxib demonstrated a significant analgesic effect on day 2 (the day after surgery), with mean SPI-24 scores $22 \%(p<0.001)$ lower in the parecoxib group relative to placebo (Fig. 2). This corresponds to an absolute difference of 7.7 points, on a scale from 0 to 72 , between the treatment groups. Likewise, SPI-24 scores were also significantly lower in the parecoxib group, compared with placebo, on day 3 (Fig. 2). The absolute difference between the groups was 4.9 points, which corresponds to a $17 \%(p=0.004)$ reduction in the parecoxib group relative to placebo.

In addition to lower pain intensity scores, parecoxib treatment also provided significant improvements in patient function compared with placebo (Fig. 3). Composite pain interference with function scores were reduced by $32 \%$ $(p<0.001)$ on day 2 (the day after surgery) and $27 \%(p=0.003)$ on day 3 relative to placebo. These percentages correspond to an absolute difference of 1.6 and 0.9 points (on a scale from 0 to 10 ) on day 2 and day 3, respectively.

On day 2 ( $24 \mathrm{~h}$ post initial dose of study medication) and day 3 (48 h post initial dose of study medication), treatment with parecoxib was associated with a significant opioid-sparing effect (Fig. 4). Patients in the parecoxib group consumed $28 \%$ less morphine at $24 \mathrm{~h}$ $(p=0.008)$ and $33 \%$ less morphine at $48 \mathrm{~h}$ $(p<0.001)$ relative to placebo. This corresponds to absolute reductions of 9.9 and 22.8 morphine equivalents at 24 and $48 \mathrm{~h}$, respectively.

Patients receiving parecoxib also had a reduced risk of experiencing opioid-related symptoms on day 2 (the day after surgery) and day 3 compared to patients receiving placebo (Table 3). Specifically, the risk of experiencing fatigue, drowsiness, inability to concentrate, and confusion was significantly reduced on both day 2 (the day after surgery) and day 3 in the parecoxib group compared with placebo. In addition, the risk of experiencing nausea, constipation, and retching/vomiting was significantly reduced on day 3 but not day 2 in the parecoxib group relative to placebo. The risks of dizziness, itching, and difficulty with urination were not significantly different between treatment groups on either day 2 or day 3 . The overall relative risk (RR) of experiencing $\geq 1$ $(\mathrm{RR}=0.71 ; \quad p<0.010), \quad \geq 2 \quad(\mathrm{RR}=0.55 ;$ $p<0.001)$, and $\geq 3(\mathrm{RR}=0.33 ; p<0.001)$ opioid-related symptoms was significantly lower with parecoxib compared with placebo on day 3 .

Both patient (Fig. 5a) and physician (Fig. 5b) evaluations of study medication scores were significantly different between the parecoxib and placebo groups at the time of transition 


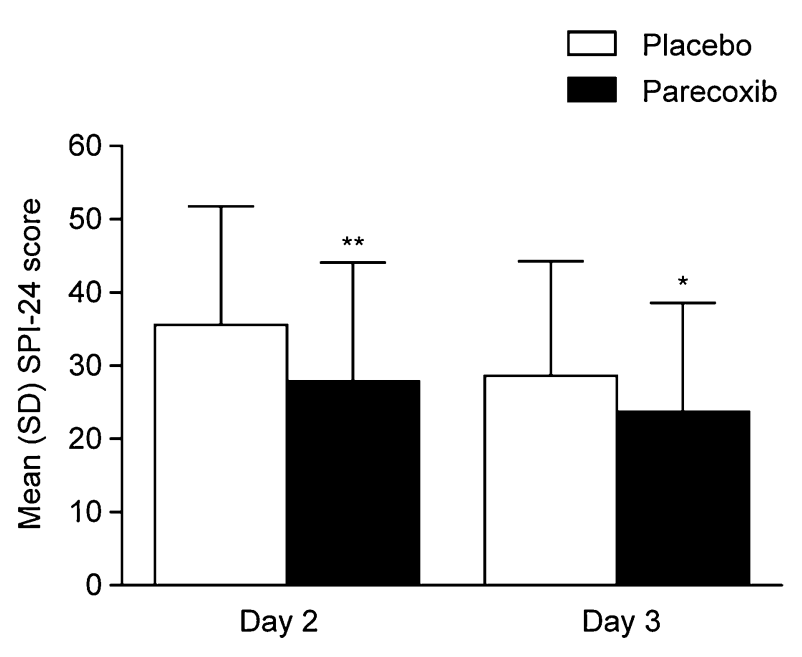

Fig. 2 Mean SPI-24 scores following surgery. ${ }^{* *} p<0.001$; ${ }^{*} p<0.010$ versus placebo. Day 2 is the day after surgery. $S D$ standard deviation, SPI-24 summed pain intensity over $24 \mathrm{~h}$

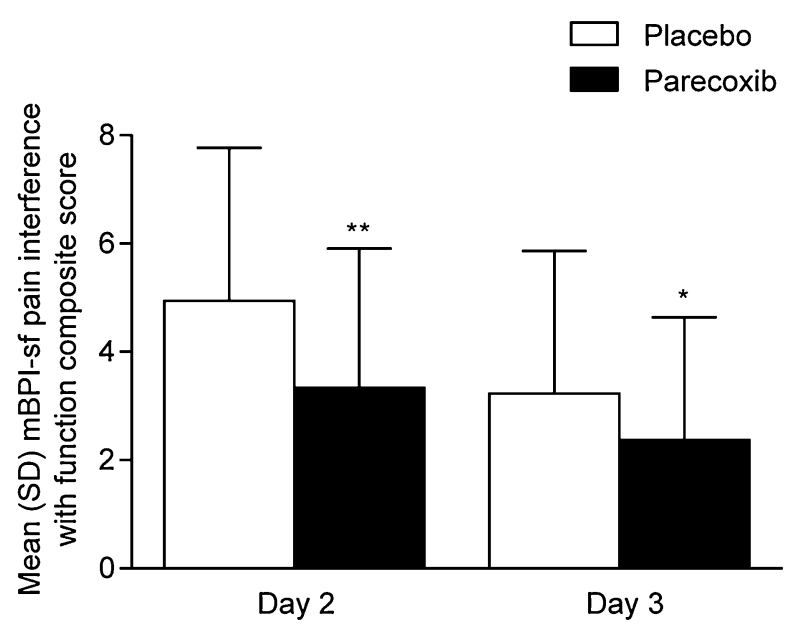

Fig. 3 Mean mBPI-sf composite pain interference with function scores following surgery. ${ }^{* *} p<0.001$ versus placebo; ${ }^{*} p<0.010$ versus placebo. Day 2 is the day after surgery. $S D$ standard deviation, $m B P I-s f$ modified brief pain inventory-short form

from IV/IM to oral dosing (both $p<0.001$ ). A greater percentage of patients $(42 \%)$ and physicians (46\%) in the parecoxib group rated their treatment as "excellent" compared with patients (21\%) and physicians (19\%) in the placebo group. Likewise, fewer patients (13\%) and physicians (8\%) in the parecoxib group rated their treatment as "poor" or "fair"

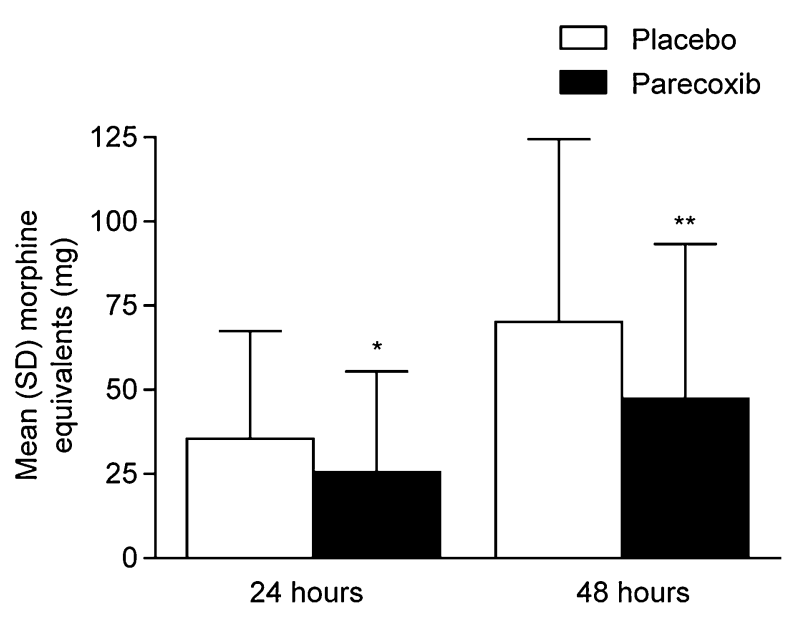

Fig. 4 Cumulative morphine consumption following initial dose of study medication. ${ }^{* *} p<0.001$ versus placebo; ${ }^{*} p<0.010$ versus placebo. $S D$ standard deviation

compared with patients (32\%) and physicians (35\%) in the placebo group.

Treatment-emergent AEs during the IV/IM phase occurred with a similar frequency in the placebo (55.8\%) and parecoxib (58.7\%) groups. The most common treatment-emergent AEs for each group are shown in Table 4. Of these AEs, nausea $($ parecoxib $=17.4 \%$; placebo $=15.9 \%$ ), vomiting (parecoxib $=9.4 \%$; placebo $=5.8 \%$ ), pruritus $($ parecoxib $=7.2 \%$; placebo $=4.3 \%)$, insomnia (parecoxib $=6.5 \%$; placebo $=2.9 \%$ ), dizziness $($ parecoxib $=2.9 \%$; placebo $=0.7 \%$ ), headache (parecoxib $=2.9 \%$; placebo $=2.2 \%$ ), fatigue $\quad($ parecoxib $=2.2 \%$; placebo $=0.0 \%$ ), and sleep disorder (parecoxib $=2.2 \%$; placebo $=0.0 \%$ ) occurred more frequently in the parecoxib group relative to placebo.

NSAIDs and COXIBs have been associated with a variety of specific adverse events including cardiovascular embolic and thrombotic events; gastrointestinal ulceration, bleeding, perforation, or hemorrhage; and bleeding. No instances of these types of events were reported among parecoxib-treated patients, with the following exception. There was one instance of myocardial infarction in a 74-year-old man reported in the parecoxib group that resulted in death of the subject; this event was deemed unrelated to the study drug or the use of opioids by the site investigator. The patient had been permanently withdrawn from 
Table 3 Frequency of opioid-related symptoms following surgery

\begin{tabular}{|c|c|c|c|c|c|c|c|c|}
\hline \multirow[t]{2}{*}{ Symptom } & \multicolumn{4}{|l|}{ Day 2} & \multicolumn{4}{|l|}{ Day 3} \\
\hline & $\begin{array}{l}\text { Parecoxib } \\
\text { (\%) }\end{array}$ & $\begin{array}{l}\text { Placebo } \\
\text { (\%) }\end{array}$ & $\mathrm{RR}^{\mathrm{a}}(95 \% \mathrm{CI})$ & $p$ value $^{a}$ & $\begin{array}{l}\text { Parecoxib } \\
(\%)\end{array}$ & $\begin{array}{l}\text { Placebo } \\
(\%)\end{array}$ & $\mathrm{RR}^{\mathrm{a}}(95 \% \mathrm{CI})$ & $p$ value $^{\mathrm{a}}$ \\
\hline Fatigue & 27 & 48 & $0.58(0.41,0.80)$ & $<0.001$ & 23 & 42 & $0.54(0.37,0.79)$ & $<0.010$ \\
\hline Drowsiness & 39 & 58 & $0.67(0.51,0.87)$ & $<0.010$ & 22 & 44 & $0.51(0.35,0.74)$ & $<0.001$ \\
\hline $\begin{array}{l}\text { Inability to } \\
\text { concentrate }\end{array}$ & 16 & 32 & $0.50(0.32,0.80)$ & $<0.010$ & 8 & 22 & $0.35(0.18,0.69)$ & $<0.010$ \\
\hline Nausea & 22 & 30 & $0.76(0.50,1.15)$ & NS & 4 & 14 & $0.28(0.11,0.72)$ & $<0.010$ \\
\hline Dizziness & 12 & 17 & $0.72(0.39,1.30)$ & NS & 9 & 12 & $0.69(0.33,1.42)$ & NS \\
\hline Constipation & 22 & 13 & $1.63(0.94,2.83)$ & NS & 18 & 34 & $0.53(0.34,0.83)$ & $<0.010$ \\
\hline Itching & 21 & 20 & $1.09(0.68,1.77)$ & NS & 13 & 13 & $0.99(0.53,1.86)$ & NS \\
\hline $\begin{array}{l}\text { Difficulty with } \\
\text { urination }\end{array}$ & 4 & 8 & $0.49(0.17,1.40)$ & NS & 2 & 3 & $0.73(0.17,3.21)$ & NS \\
\hline Confusion & 2 & 8 & $0.20(0.04,0.87)$ & $<0.050$ & 2 & 9 & $0.27(0.08,0.93)$ & $<0.050$ \\
\hline $\begin{array}{l}\text { Retching/ } \\
\text { vomiting }\end{array}$ & 13 & 18 & $0.71(0.40,1.28)$ & NS & $0^{\mathrm{b}}$ & 6 & - & - \\
\hline
\end{tabular}

$N S$ non-significant, $R R$ relative risk

${ }^{a}$ Parecoxib compared to placebo

${ }^{b}$ It was not possible to calculate the RR since no patients in the parecoxib group experienced retching/vomiting

the study because of elevated creatinine and urea nitrogen in the blood after 2 days of treatment (the day after surgery). The myocardial infarction occurred 3 days after discontinuation of treatment.

\section{DISCUSSION}

Pain control is directly related to fast recovery, early rehabilitation, and patient satisfaction after orthopedic surgeries such as total joint replacement [10-12]. In this subset analysis of patients undergoing major orthopedic surgery, postoperative administration of parecoxib resulted in significantly lower pain scores relative to placebo on day 2 (the day after surgery) and day 3 following surgery. Pain interference with function scores, which are a composite score that examines how pain affects general activity, mood, walking ability, relations with others, and sleep, were also significantly better with parecoxib compared with placebo. These data demonstrate that parecoxib provides clinically meaningful improvement in pain and patient function following orthopedic surgery. Indeed, a large percentage of both patients (42\%) and physicians (46\%) rated parecoxib treatment as "excellent" during the study.

Opioids can elicit a variety of adverse events that slow patient recovery and rehabilitation, and current treatment guidelines recommend a multimodal treatment approach that incorporates other agents to provide supplemental analgesia and reduce overall opioid consumption [13, 15-17, 20, 27]. In the current study, parecoxib significantly reduced overall postoperative opioid consumption, compared to placebo, and decreased the occurrence of multiple opioid-related adverse events.

Pain and pain control following orthopedic surgery vary according to procedure and the type of anesthesia utilized [28]. Pain control after hip replacement, for example, is 


\section{A Patient score}

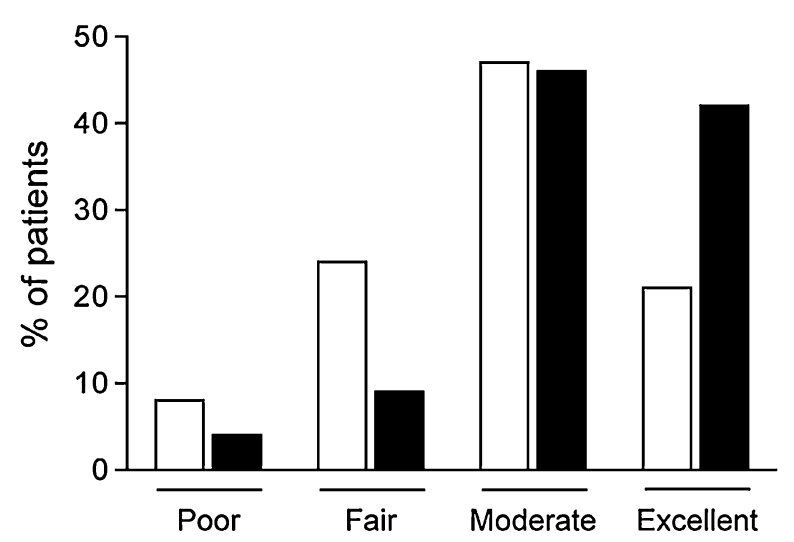

\section{B Physician score}

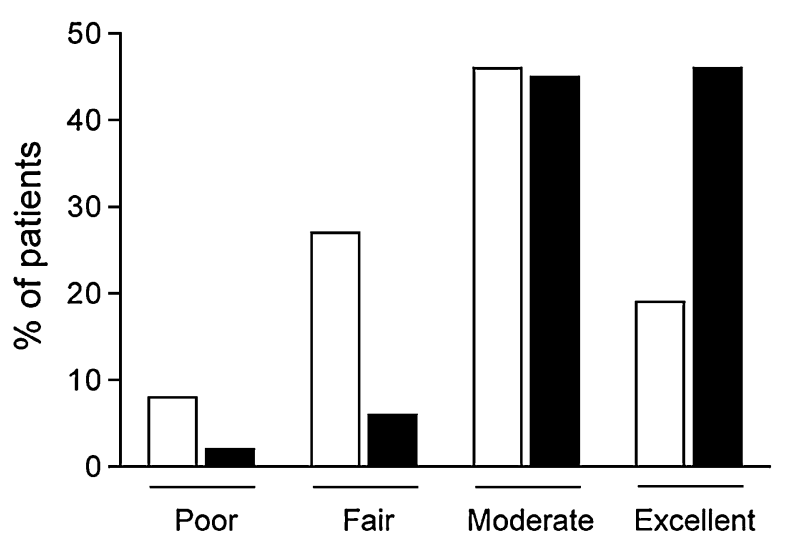

Fig. 5 Patient (a) and physician (b) global evaluation of study medication scores at the time of transition from IV/IM to oral dosing

considered easier than after knee replacement $[29,30]$. In addition, pain and recovery following total joint replacement can be significantly worse using general anesthesia compared with spinal or epidural approaches [31, 32]. Our study is the first, to our knowledge, to combine several types of orthopedic procedures and analyze them as a single heterogeneous group. However, our findings are in broad agreement with previous placebo-controlled studies of parecoxib in specific orthopedic surgery models. For example, significant improvements in postoperative pain have been associated with multiple dose parecoxib in patients undergoing total hip arthroplasty [33, 34], total knee arthroplasty $[35,36]$, and a variety of spinal procedures including spinal fusion [37]. In nearly all these trials, parecoxib also reduced total postoperative opioid consumption compared to placebo [33, 35-37].

In our clinical trial setting, it is recognized that AEs can result from the use of study treatment, rescue opioids (which were available to both placebo and parecoxib treatment groups), or the surgical procedure itself. In our analysis, the overall frequency of AEs was similar in the parecoxib and placebo groups and, with the exception of nausea, no specific $\mathrm{AE}$ was reported in more than $10 \%$ of patients in either treatment group. Certain AEs, however, occurred more frequently in the parecoxib group including nausea, vomiting, pruritus, insomnia, dizziness, headache, fatigue, and sleep disorder.

Our study is also limited in that it was a subset analysis of patients from a clinical trial that was not powered specifically to look at the outcomes assessed here [25]. However, the number of patients included in our analysis is large and on par with previous trials of parecoxib for postoperative pain. Our analysis is also limited in that the original clinical trial did not specifically assess movement-related pain, which is particularly important in patients following orthopedic surgery. Parecoxib has been shown to relieve movement-related pain following gynecological surgery $[38,39]$ and total hip arthroplasty (in press). Additionally, a previous placebo-controlled study has shown that parecoxib results in improved range of motion, relative to placebo, following total knee replacement [35].

The patients included in our analysis received parecoxib postoperatively, though studies have shown that traditional NSAIDs and some COXIBs may provide preemptive analgesia and demonstrate greater pain relief when administered 30-45 min prior to surgery $[40,41]$. Traditional NSAIDs, however, inhibit platelet function and may increase bleeding time. Parecoxib does not affect platelet function, making it a potentially attractive preoperative analgesic option [21, 22]. Though 
Table 4 Frequency of most common treatment-emergent AEs

\begin{tabular}{lcc}
\hline AE, $\boldsymbol{n}$ (\%) & Parecoxib & Placebo \\
\hline Any AE & $81(58.7)$ & $77(55.8)$ \\
Nausea & $24(17.4)$ & $22(15.9)$ \\
Vomiting & $13(9.4)$ & $8(5.8)$ \\
Constipation & $13(9.4)$ & $13(9.4)$ \\
Pruritus & $10(7.2)$ & $6(4.3)$ \\
Insomnia & $9(6.5)$ & $4(2.9)$ \\
Anemia & $5(3.6)$ & $5(3.6)$ \\
Dizziness & $4(2.9)$ & $1(0.7)$ \\
Headache & $4(2.9)$ & $3(2.2)$ \\
Procedural nausea & $4(2.9)$ & $4(2.9)$ \\
Fatigue & $3(2.2)$ & $0(0.0)$ \\
Sleep disorder & $3(2.2)$ & $0(0.0)$ \\
Anemia postoperative & $3(2.2)$ & $3(2.2)$ \\
Dyspepsia & $3(2.2)$ & $4(2.9)$ \\
Pyrexia & $2(1.4)$ & $12(8.7)$ \\
Musculoskeletal stiffness & $1(0.7)$ & $3(2.2)$ \\
Body temperature increased & $1(0.7)$ & $17(12.3)$ \\
Muscle spasms & $0(0.0)$ & $4(2.9)$ \\
\hline Occurting in & &
\end{tabular}

Occurring in $\geq 2 \%$ of patients in either treatment group during the IV/IM treatment phase

parecoxib provides an analgesic benefit when administered preoperatively or postoperatively, few studies have compared timing of parecoxib administration, and the results are mixed. Preoperative administration of parecoxib provided greater pain relief compared to postoperative administration in trials of general surgery and total hip replacement $[42,43]$. In another study of total hip replacement, however, there was no significant difference in pain severity or total opioid consumption between pre- and postoperative administration of parecoxib [44]. Additionally, there was no difference in analgesia and opioid-related adverse events between preand postoperative administration of parecoxib in patients following colorectal surgery [45]. Further studies are required to determine whether preoperative administration of parecoxib offers any advantages over postoperative administration in patients undergoing orthopedic procedures. Currently, Procedure Specific Postoperative Pain Management (PROSPECT) guidelines recommend COXIBs, such as parecoxib, as postoperative analgesia following total knee or hip arthroplasty [28].

\section{CONCLUSION}

Overall, postoperative administration of parecoxib provided significant analgesic and opioid-sparing effects in our analysis. Thus, the data suggest that parecoxib is a good option for patients following orthopedic surgeries, which often depend on early mobilization and physical rehabilitation for successful outcomes.

\section{ACKNOWLEDGEMENTS}

Sponsorship and article processing charges for this study were funded by Pfizer Inc. All authors had full access to all of the data in this study and take complete responsibility for the integrity of the data and accuracy of the data analysis. All named authors meet the International Committee of Medical Journal Editors (ICMJE) criteria for authorship for this manuscript, take responsibility for the integrity of the work as a whole, and have given final approval for the version to be published. Medical writing support was provided by Matt Soulsby PhD, CMPP of Engage Scientific Solutions and was funded by Pfizer Inc. Portions of this analysis were presented at the American Society of Anesthesiologists (ASA) anesthesiology annual meeting, Oct 24-28, 2015, San Diego, CA, USA.

Disclosures. Margaret Noyes Essex is a full-time employee of, and owns stock in, Pfizer. Patricia Salomon is a full-time employee of, and owns stock in, Pfizer. Bruce Parsons is a full-time employee of, and owns stock in, Pfizer. Chunming $\mathrm{Li}$ is a full-time employee of, and owns stock in, Pfizer. Raymond Cheung is a full-time 
employee of, and owns stock in, Pfizer. Efrain Diaz-Borjon serves as a consultant to Zimmer-Biomet. Armando Torres-Gomez has served as a speaker for Pfizer Inc.

Compliance with Ethics Guidelines. The study was approved by an institutional review board or independent ethics committee at each investigational center and patients provided written informed consent before participation. The study was conducted in compliance with the Declaration of Helsinki of 1964, as revised in 2013, and all International Conference on Harmonization Good Clinical Practice Guidelines.

Data Availability. Pfizer provides access to detailed clinical data in response to legitimate requests from researchers and regulators. http:// www.pfizer.com/research/clinical_trials/trial_ data_and_results.

Open Access. This article is distributed under the terms of the Creative Commons Attribution-NonCommercial 4.0 International License (http://creativecommons.org/licenses/ by-nc/4.0/), which permits any noncommercial use, distribution, and reproduction in any medium, provided you give appropriate credit to the original author(s) and the source, provide a link to the Creative Commons license, and indicate if changes were made.

\section{REFERENCES}

1. Agency for Healthcare Research and Quality. Most frequent procedures performed in US hospitals, 2010. 2013. http://www.hcup-us.ahrq.gov/reports/ statbriefs/sb149.pdf. Accessed 14 March 2016.

2. American Academy of Orthopaedic Surgeons. Annual incidence of common musculoskeletal procedures and treatment. 2014. http://www.aaos.org/cc_files/ aaosorg/research/stats/commonprocedurestreat ments-march2014.pdf. Accessed 14 March 2016.

3. Kurtz S, Ong K, Lau E, Mowat F, Halpern M. Projections of primary and revision hip and knee arthroplasty in the United States from 2005 to 2030. J Bone Joint Surg. 2007;89:780-5.
4. Chung F, Ritchie E, Su J. Postoperative pain in ambulatory surgery. Anesth Analg. 1997;85:808-16.

5. Gramke HF, de Rijke JM, van Kleef M, et al. The prevalence of postoperative pain in a cross-sectional group of patients after day-case surgery in a university hospital. Clin J Pain. 2007;23:543-8.

6. Wylde V, Rooker J, Halliday L, Blom A. Acute postoperative pain at rest after hip and knee arthroplasty: severity, sensory qualities and impact on sleep. Orthop Traumatol Surg Res. 2011;97:139-44.

7. Barlow T, Griffin D, Barlow D, Realpe A. Patients' decision making in total knee arthroplasty: a systematic review of qualitative research. Bone Joint Res. 2015;4:163-9.

8. Parvizi J, Della Valle CJ, Viscusi ER. Undermanaged pain in the orthopedic surgical patient: techniques to improve outcomes. 2016. http://www.medscape. org/viewarticle/556201. Accessed 14 March 2016.

9. Scott CE, Howie CR, MacDonald D, Biant LC. Predicting dissatisfaction following total knee replacement: a prospective study of 1217 patients. J Bone Joint Surg Br. 2010;92:1253-8.

10. Scuderi GR. The challenges of perioperative pain management in total joint arthroplasty. Am J Orthop (Belle Mead NJ). 2015;44:S2-4.

11. Barrington JW. Fast-track recovery and outpatient joint arthroplasty. Am J Orthop (Belle Mead NJ). 2015;44:S21-2.

12. Lamplot JD, Wagner ER, Manning DW. Multimodal pain management in total knee arthroplasty: a prospective randomized controlled trial. J Arthroplast. 2014;29:329-34.

13. Zhao SZ, Chung F, Hanna DB, Raymundo AL, Cheung RY, Chen C. Dose-response relationship between opioid use and adverse effects after ambulatory surgery. J Pain Symptom Manag. 2004;28:35-46.

14. Apfelbaum JL, Gan TJ, Zhao S, Hanna DB, Chen C. Reliability and validity of the perioperative opioid-related symptom distress scale. Anesth Analg. 2004;99:699-709.

15. Wheeler M, Oderda GM, Ashburn MA, Lipman AG. Adverse events associated with postoperative opioid analgesia: a systematic review. J Pain. 2002;3:159-80.

16. Oderda GM, Evans RS, Lloyd J, et al. Cost of opioid-related adverse drug events in surgical patients. J Pain Symptom Manage. 2003;25:276-83. 
17. Oderda GM, Said Q, Evans RS, et al. Opioid-related adverse drug events in surgical hospitalizations: impact on costs and length of stay. Ann Pharmacother. 2007;41:400-6.

18. Ljungqvist O. ERAS-enhanced recovery after surgery: moving evidence-based perioperative care to practice. JPEN J Parenter Enteral Nutr. 2014;38:559-66.

19. Kehlet H, Wilmore DW. Multimodal strategies to improve surgical outcome. Am J Surg. 2002;183:630-41.

20. The American Society of Anesthesiologists Task Force on Acute Pain Management. Practice guidelines for acute pain management in the perioperative setting: an updated report by the American Society of Anesthesiologists Task Force on Acute Pain Management. Anesthesiology. 2012;116:248-73.

21. Leese PT, Hubbard RC, Karim A, Isakson PC, Yu SS, Geis GS. Effects of celecoxib, a novel cyclooxygenase-2 inhibitor, on platelet function in healthy adults: a randomized, controlled trial. J Clin Pharmacol. 2000;40:124-32.

22. Noveck R, Laurent A, Kuss M, Talwalker S, Hubbard R. Parecoxib sodium does not impair platelet function in healthy elderly and non-elderly individuals. Clin Drug Investig. 2001;21:465-76.

23. Hawkey CJ. COX-1 and COX-2 inhibitors. Best Pract Res Clin Gastroenterol. 2001;15:801-20.

24. Rostom A, Muir K, Dubé C, et al. Gastrointestinal safety of cyclooxygenase- 2 inhibitors: a Cochrane Collaboration systematic review. Clin Gastroenterol Hepatol. 2007;5:818-28 (28 e1-5; quiz 768).

25. Nussmeier NA, Whelton AA, Brown MT, et al. Safety and efficacy of the cyclooxygenase- 2 inhibitors parecoxib and valdecoxib after noncardiac surgery. Anesthesiology. 2006;104:518-26.

26. Mendoza T, Mayne T, Rublee D, Cleeland C. Reliability and validity of a modified Brief Pain Inventory short form in patients with osteoarthritis. Eur J Pain. 2006;10:353-61.

27. Raeder J. Opioids in the treatment of postoperative pain: old drugs with new options? Expert Opin Pharmacother. 2014;15:449-52.

28. Procedure Specific Postoperative Pain Management (PROSPECT). http://www.postoppain.org/whyprospect/. Accessed 12 Nov 2016.

29. O'Brien S, Bennett D, Doran E, Beverland DE. Comparison of hip and knee arthroplasty outcomes at early and intermediate follow-up. Orthopedics. 2009;32:168.
30. Johansson Stark A, Charalambous A, Istomina $\mathrm{N}$, et al. The quality of recovery on discharge from hospital, a comparison between patients undergoing hip and knee replacement-a European study. J Clin Nurs. 2016;25:2489-501.

31. Perlas A, Chan VW, Beattie S. Anesthesia technique and mortality after total hip or knee arthroplasty: a retrospective, propensity score-matched cohort study. Anesthesiology. 2016;125:724-31.

32. Sibia US, MacDonald JH, King PJ. Predictors of hospital length of stay in an enhanced recovery after surgery program for primary total hip arthroplasty. J Arthroplast. 2016;31:2119-23.

33. Malan TP Jr, Marsh G, Hakki SI, Grossman E, Traylor L, Hubbard RC. Parecoxib sodium, a parenteral cyclooxygenase 2 selective inhibitor, improves morphine analgesia and is opioid-sparing following total hip arthroplasty. Anesthesiology. 2003;98:950-6.

34. Viscusi ER, Gimbel JS, Halder AM, Snabes M, Brown MT, Verburg KM. A multiple-day regimen of parecoxib sodium $20 \mathrm{mg}$ twice daily provides pain relief after total hip arthroplasty. Anesth Analg. 2008;107:652-60.

35. Zhu Y, Wang $\mathrm{S}, \mathrm{Wu} \mathrm{H}, \mathrm{Wu}$ Y. Effect of perioperative parecoxib on postoperative pain and local inflammation factors PGE2 and IL-6 for total knee arthroplasty: a randomized, double-blind, placebo-controlled study. Eur J Orthop Surg Traumatol. 2014;24:395-401.

36. Hubbard RC, Naumann TM, Traylor L, Dhadda S. Parecoxib sodium has opioid-sparing effects in patients undergoing total knee arthroplasty under spinal anaesthesia. Br J Anaesth. 2003;90:166-72.

37. Jirarattanaphochai K, Thienthong S, Sriraj W, et al. Effect of parecoxib on postoperative pain after lumbar spine surgery: a bicenter, randomized, double-blinded, placebo-controlled trial. Spine (Phila Pa 1976). 2008;33:132-9.

38. Barton SF, Langeland FF, Snabes MC, et al. Efficacy and safety of intravenous parecoxib sodium in relieving acute postoperative pain following gynecologic laparotomy surgery. Anesthesiology. 2002;97:306-14.

39. Bikhazi GB, Snabes MC, Bajwa ZH, et al. A clinical trial demonstrates the analgesic activity of intravenous parecoxib sodium compared with ketorolac or morphine after gynecologic surgery with laparotomy. Am J Obstet Gynecol. 2004;191:1183-91.

40. Ong CK, Lirk P, Seymour RA, Jenkins BJ. The efficacy of preemptive analgesia for acute 
postoperative pain management: a meta-analysis. Anesth Analg. 2005;100:757-73 .

41. Feng Y, Ju H, Yang B, An H. Effects of a selective cyclooxygenase-2 inhibitor on postoperative inflammatory reaction and pain after total knee replacement. J Pain. 2008;9:45-52.

42. Bajaj P, Ballary CC, Dongre NA, Baliga VP, Desai AA. Role of parecoxib in pre-emptive analgesia: comparison of the efficacy and safety of pre- and postoperative parecoxib in patients undergoing general surgery. J Indian Med Assoc. 2004;102:272,4,6-8.

43. Bao Y, Fang J, Peng L, et al. Comparison of preincisional and postincisional parecoxib administration on postoperative pain control and cytokine response after total hip replacement. J Int Med Res. 2012;40:1804-11.

44. Martinez V, Belbachir A, Jaber A, et al. The influence of timing of administration on the analgesic efficacy of parecoxib in orthopedic surgery. Anesth Analg. 2007;104:1521-7.

45. Pandazi A, Kapota E, Matsota P, Paraskevopoulou P, Dervenis C, Kostopanagiotou G. Preincisional versus postincisional administration of parecoxib in colorectal surgery: effect on postoperative pain control and cytokine response. A randomized clinical trial. World J Surg. 2010;34:2463-9. 